\title{
Using threshold co-integration to estimate asymmetric price transmission in the Turkish milk market
}

\author{
Ozgur Bor*, Berna TuncaY**
}

DOI: $10.30682 / \mathrm{nm} 2101 \mathrm{i}$

JEL codes: C24, D43, L11, Q11

\begin{abstract}
We investigate the price dynamics between retail milk price and raw milk price in the Turkish fluid milk market. The study uses monthly fluid milk prices for 14 years between January 2003 and December 2016. We analyze the price adjustment in the fluid milk market through an asymmetric error correction model with threshold co-integration. We find that the transmission between the two prices has been asymmetric in both the long term and short term period. Differences between the farm milk prices and retail milk prices may exist due to marketing costs across the supply chain and pricing policies associated with the market structure. Results of the long-run analysis indicate a significant market power in the fluid milk market. Therefore, in this asymmetric case, the deviations are likely to be the reason for the market power of the processors/retailers and the reason for the oligopolistic market structure in the sector.
\end{abstract}

Keywords: Asymmetric price transmission, Error correction model, Threshold co-integration, TAR, M-TAR, Consistent threshold, Fluid milk market, Turkey.

\section{Introduction}

Price transmission and market integration have been very important topics in the fields of industrial organization and other areas of applied microeconomics, especially for the study of price relationship in agricultural commodity markets, that can shed light on the stability of prices. With rapidly changing market structures and growing concentration and centralization of processing and retailing firms, the questions of how quickly farm prices are transmitted to the retail level and what the incidence of costs is on retail prices have attracted much attention. Given the price is the primary mechanism in the related markets, the extent of adjustment and speed of shocks transmitted between producer and retailer prices are significant factors showing the behavior of actors at various market levels (Abdulai, 2002). As indicated in Peltzman (2000), asymmetric price transmission is the rule rather than the exception, and various studies have revealed that asymmetric price transmissions are quite common, especially in the agricultural industry.

Price transmission can be defined as the relationship between the prices in the two related

\footnotetext{
* Department of Economics, Atılım University, Gölbaşı, Ankara, Turkey.** Regional Researches Center on Horticulture and Organic Agriculture (CRRHAB), Sousse, Tunisia.

** Department of Economics, Koç University, Sariyer, Istanbul, Turkey.

Corresponding author: betuncay@ku.edu.tr
} 
markets. Price transmission is used to demonstrate the effects of a price change in one market over another and provides information on the extent of these markets. The important issue is whether the transmission is symmetric or asymmetric. A symmetric price transmission integrates markets vertically and horizontally and a change in prices in one market is quickly reflected to another. Therefore, a change in prices in one market will have an equal and immediate effect on the prices in other related market. But, if the price transmission between the specific stages of the supply chain is asymmetric, then the price changes at the production level are not transmitted to the price changes at the processing and/or retailing level quickly or fully as in the case of a symmetric transmission.

There are several reasons for incomplete asymmetric price transmissions (APT); such as asymmetric information among the firms (Bailey and Brorsen, 1989), market power and concentration at processing and retailing levels (Peltzman, 2000; Meyer and von Cramon-Taubadel, 2004; Azzam, 1999), interaction between market power and economy of scale (Lloyd et al., 2006), adjustment and menu costs (Meyer and von Cramon-Taubadel, 2004; Bailey and Brorsen, 1989). Moreover, supply shocks due to adverse weather conditions, and political uncertainty can contribute to high level of prices and the immediate impact would be a fall in the real income of households in real terms (Ghoshray, 2011). Literature on asymmetric price transmission mostly refers to non-competitive market structures such as market power and oligopolistic behavior as an explanation for asymmetry (Vavra and Goodvin, 2005). Brown and Yucel (2000) consider oligopolistic firms engaging in unspoken collusion to maintain higher profits. Ward (1982) suggests that market power can lead to a negative asymmetric price transmission if oligopolists are reluctant to risk their market share by increasing the output prices. Meyer and von Cramon-Taubadel (2004) state that market power can lead to long term asymmetries in the magnitude of adjustment. An important sign of the market power is the existence of price asymmetries which indicate an unbalanced relationship between the price increases and decreases for a product through the farm gate and retail stages. More specifically, price asymmetries could be negative or positive depending on its effect. A positive (negative) price asymmetry occurs when a decrease (increase) in prices at the farm level is not fully or immediately transmitted, but an increase and/or decrease passes more quickly or fully to the final consumer (Meyer and von Cramon-Taubadel, 2004; Vavra and Goodwin, 2005). Price asymmetries are important because, usually, it negatively affects the welfare (Meyer and von Cramon-Taubadel, 2004; Hahn, 1990). In case of vertical asymmetric price transmission, consumers often feel the increasing effect of farm prices that are more fully and rapidly transmitted to retail levels than the equivalent decreases (Kinnucan and Forker, 1987). Similarly, Capitanio et al. (2019) investigates asymmetric vertical transmission of price and shows smaller positive effects on consumer welfare and a potential rise in rents for the firms in the Italian hog market. Therefore, we can assume that in case of vertical asymmetries, the value is acquired not in the production stage but inside the supply chain, and that the real winners are not the producers or the consumers (final users), but the holders of the last stage, where the goods are sold to the final consumers.

Price transmission is generally measured by the price transmission elasticity, which is the percentage change in price of one market to a given percentage change in price of another market. If such relationship between two prices exists in the long run, the markets are said to be integrated. This relationship may not hold in the short run due to deviations that can be driven by shocks in one price not being transmitted to the other price. The price transmission elasticity has been estimated by unit root tests and Error Correction Models (ECM) with threshold adjustment (Enders and Siklos, 2001; Meyer and von Crauben-Taubadel, 2004; Frey and Manera, 2007). Threshold adjustment analysis has a particular importance because it implies that movements toward long run equilibrium do not take place at all points in time but only when the divergence from equilibrium exceeds the threshold (Ghoshray, 2011). Abdulai (2002) employs threshold co-integration tests that allow for asymmetric 
adjustment towards a long-run equilibrium to examine the relationship between producer and retail pork prices in Switzerland. The short-run adjustments are also examined with asymmetric error correction models in the paper. The results show that price transmission between the producer and retail levels is asymmetric. Ghoshray (2002) examines price differentials for the international wheat market by employing a co-integration model with Threshold Autoregressive (TAR) and Momentum Threshold Autoregressive (M-TAR) adjustments and finds that the world wheat market is highly integrated with a little evidence of asymmetry. Jaffry (2004) estimates an asymmetric error correction price transmission model for the whole fresh French hake value chain and tests for the co-integration between auction and retail prices using the Engle and Granger two-step method, the Enders and Granger Threshold Autoregression (TAR) and Momentum Autoregression (M-TAR) methodologies. The results indicate an obvious evidence of asymmetric price transmission in the whole hake value chain. Ghoshray (2008) tests the presence of co-integration within the asymmetric adjustment between the rice export prices of Vietnam and Thailand. The results show that the nature of asymmetry is captured by the M-TAR model and the path of adjustment to the long run equilibrium relation is relatively faster when the price differential is decreasing compared to the case when the price differential is increasing. Ghoshray (2011) tests how international commodity prices are transmitted to domestic prices for 13 country/commodity pairs by using a TAR/M-TAR model and concludes that for the two key commodities, coffee and sugar, there is an evidence of difference-stationary behavior.

Asymmetric price transmission has recently attracted considerably high attention in the agricultural economics. There is a rich literature on the interactions along the dairy marketing chain, on the other hand, existing research has rarely been conducted for Turkey as a developing country of the world where the farm-retail price transmission of fluid milk represents an interesting case as an important food commodity. For instance; Bor et al. (2014) finds asymmetry in the Turkish fluid milk market by applying a standard asymmetric error correction model on the monthly prices between January 2003 and December 2012. The results of the paper imply that retailers as well as processors exercise significant market power in the Turkish milk market. Çınar (2017) applies a Vector Error Correction Model (VECM) to monthly price data from January 2003 to December 2016 for farm milk prices and retail cheese and yoghurt prices and finds that there is an asymmetric price transmission between producer and retailer market. Thus, both above mentioned studies support the presence of asymmetric pricing behavior in Turkey. Moreover, Tekgüç (2013) employs Threshold Autoregressive (TAR) and Moment Threshold Autoregressive (M-TAR) models to analyse the relationship between the farm milk prices and wholesale UHT (Ultra-High Temperature) packed milk prices. The author shows evidence for a downward movement in wholesale milk prices while farm gate prices do not decrease correspondingly.

The pricing behaviors in the raw milk market at the farm gate and in the fluid milk market at the retailer shelves are somehow interesting in Turkey. There is a government intervention over the farm gate prices where the National Milk Council makes an announcement to determine a reference price for a raw milk product. In most cases, the reference price is accepted as the ceiling farm gate price in the industry. Also, government subsidizes milk by giving a premium per liter and these payments are done in every three months. For example, the raw milk price was $1.15 \mathrm{TL}$ (0.4356 USD) per liter in April 2015 and there was 0.06 TL (0.0227 USD) premium per liter to the producer. The average retail price was $3.50 \mathrm{TL}$ which was equivalent to 1.325 USD for a daily fluid milk in April 2015 and there was no intervention to the retail prices by any authority. The costs of distribution, processing, and packaging are well defined factors affecting the prices, but still the difference between the farm gate and retail prices may not be easily explained. Farmers at the beginning and consumers at the end of the marketing chain often suspect that imperfect competition in processing and retailing allows middlemen to abuse the market power. This situation raises 
the questions of how the farm prices are transmitted to the retail price levels if there is an imperfect competition that exists in processing and retailing sectors allowing middlemen to abuse the market power in Turkey. There are empirical studies in literature on asymmetric price transmission referring to anti-competitive market structures (Kinnucan and Forker, 1987; Miller and Hayenga, 2001). These studies investigate imperfect competition in processing and retailing that allows middlemen to use the market power. They generally conclude that monopoly power causes positive price asymmetry (Meyer and von Cramon-Taubadel, 2004). Therefore, we aim to investigate the same issue for Turkey and test raw milk and retail fluid milk price transmissions by employing TAR and M-TAR specifications to contribute to the literature and to provide insights that should signal to policy makers for improving the dairy market structure. Thus, we particularly aim to demonstrate how changes in the prices of one market are transmitted to another, which provides information on the extent of the market and whether markets are operating efficiently. Our focus is on vertical asymmetry in price transmission between different stages of a marketing chain, therefore we estimate the final error correction model of price transmission.

The paper is organized as follows. Section 2 summarizes an overview of the dairy sector in Turkey. Empirical strategy is provided in Section 3. Data, and empirical results are explained in Section 4. Finally, concluding remarks are given in Section 5.

\section{Institutional background in the Turkish fluid milk market}

In the last decade, dairy-processing industry in Turkey has received a considerable investment, and the number of modern milk processing plants has increased. Many investments on the dairy processing industry have become equipped with high technology, and the result was indeed an increase in the milk production affecting the price of raw milk products. Also, the industry faced with the new labels entering the market, with most of the retail chains producing their own brands and introducing a competition to the other brands in the market. Parallel to this increase in the number of processing firms, the amount of milk produced and processed has also increased in the market. In this respect, there are eight dairy processing or affiliated companies among the top 500 Turkish companies.

Turkey is among the 10 largest milk producers in the world (FAO, 2014). The total annual milk production exceeded 18 billion liters in 2013. In 2013, of the total production, the amount of milk collected by the industry was around 8 million tons and the registered milk production was $46.66 \%$ of the total production in 2012 (SIS, 2014). It is estimated that on average 3 billion liters are used by farm families for their own consumption or processing, 1 billion liters are handled by street vendors, over 2 billion liters are processed by mandiras (small, simple processing establishments) and well over 3.5 billion liters are processed by medium and large-sized dairies. A significant number of mandiras are run seasonally and they are unregistered. Most of the unregistered milk is handled outside of any formal quality control, unpasteurized and unpacked (Dellal and Berkum, 2009). It is reported that the registered milk production is increased approximately to $50 \%$ of the total production in recent years (Turkstat, milk and milk products various years).

The production costs of milk are high in Turkey and raw-milk producers work with low-profit margins due to these high costs. The producer revenue primarily consists of the sales of the milk, and secondarily, the sales of the animals (most dairy farms sell the male calves born by their cows and heifers), making the cost of production undoubtedly important. Therefore, the key determinant of the profit is the cost of the production (DairyCo, 2012). But as the initial investment and production costs are high in Turkey, ${ }^{1}$ the level of the raw milk price is significantly important for the farmers. On the other hand, consumption level of liquid milk is very

1 Average production costs consist of around $70 \%$ feed, $20 \%$ employee and $6 \%$ health and surveillance according to Bor, 2014. 
low in the Turkish market; the most common form of milk consumption is yoghurt, followed by white cheese (feta type) and ayran, a liquid salted milk drink. The annual per capita consumption of milk in Turkey is $37.3 \mathrm{~kg}$ of milk equivalence that is considerably low compared to the other developed countries (FAO, 2014). In 2012, EU-27 had $288.3 \mathrm{~kg}$ and North America had $274 \mathrm{~kg}$ of milk equivalence (FAO, 2014). The final liquid milk prices on the retail shelves play an important role affecting the consumption level. The consumers argue that the retail price of milk is considerably high in Turkey while the producers argue that the raw milk price is low. Fluid milk market in Turkey is subject to volatile input prices for the producers and volatile final prices for the consumers.

Figure 1 shows that there is a large marketing margin in the Turkish fluid milk market over a long period of time. When we consider the amount of daily milk sold in the market, we see that the margin increases. We also observe that the retail price is being completely unrelated to the farm gate price below a certain threshold. ${ }^{2}$ Accordingly, the two prices are related in a nonlinear manner; increases in the farm gate price of the fluid milk (leading to a decline in marketing margins) are transmitted to the retail level rapidly, on the other hand, decreases in the farm gate price of the fluid milk (leading to an increase in the marketing margins) are transmitted to the retail level slowly. If a decrease in farm gate prices is not fully transmitted to retail prices, then reductions in supply and increases in demand, that would have otherwise occurred, will not take place. This would make the price decrease more acute and prolonged. Thus, we can assume that the retailers as well as the processors adjust the prices partly to the changes in demand and supply.

The marketing of the raw milk by the producers is restricted in Turkey such that, the producer

Figure 1 - The farm gate and the retail price of fluid milk (averages of daily and Ultra-High Temperature (UHT) milk together) between 2003/01-2016/12.

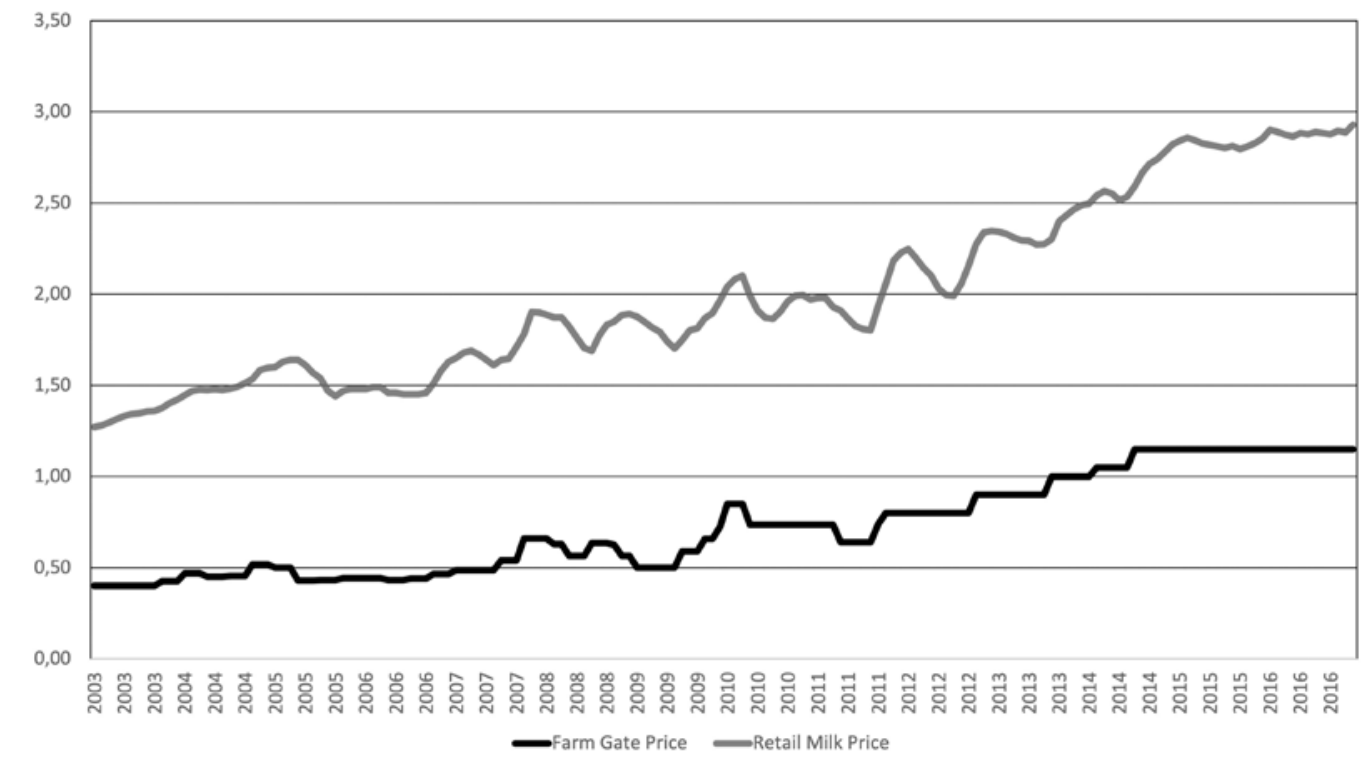

Source: Data obtained from Turkish Statistical Institute (Turkstat).

\footnotetext{
2 Retail price fluctuations are not thoroughly affected by farm gate price changes and despite the fact that farm gate prices are set fixed at $1.15 \mathrm{TL}$ in 2015 , retail prices continued to fluctuate supporting this fact.
} 
and consumer one to one interaction is not available. ${ }^{3}$ Therefore, small farmers can only operate through small processors (mandiras) and/or through supplying their production to the big processors. ${ }^{4}$ The big processors collect milk by their own cooled trucks and look for suppliers for enough daily raw milk in order to decrease the transaction cost (they are not willing to collect partial quantities). Therefore, only middle and big dairy farms have little bargaining ability for the price and quality (Hatirli, 2004).

The Turkish fluid milk market is highly concentrated. Only few big and traditional brands (SEK, Danone, AOC, Yorsan, Ulker, Pinar) are competing with each other in the market. Although there are new entrants, the market especially has several retailers' own brands in the UHT segment, and the market is still squeezed by the conventional ones. Moreover, in the retail sector, few retailers are spread all over the country although some domestic brands are operating at a regional level. Especially, there are few well known big retailers at the central/crowded cities. Thus, the above mentioned fluid milk brands are dominant on the shelves of these retailers in the country.

\section{Empirical strategy}

Nonlinearities and asymmetric adjustment are important issues to be addressed. This is true especially when the aim of the model is to take into account a threshold mechanism, which causes a different adjustment to transmission of price signals. We employ the Engle and Granger two step method (1987) to test for the co-integration between the two prices. We assume a symmetric adjustment and use two step methodology to estimate the long run equilibrium relationship.
We employ ordinary least squares method to estimate the long run relation which is given by equation (1):

$$
\mathrm{RMP}_{\mathrm{t}}=\alpha+\beta \mathrm{FGP}_{\mathrm{t}}+\mu_{\mathrm{t}}
$$

Here, RMP is the retail milk price and FGP is the farm gate price of fluid milk. RMP and FGP are non-stationary I(1) prices, " $\alpha$ " is an arbitrary constant which accounts for transfer costs and quality differences, " $\beta$ " is the price transmission elasticity and " $\mu$ " is the error term that can be serially correlated. Engle and Granger (1987) show that the co-integration exists if $\mu_{\mathrm{t}} \sim \mathrm{I}(0)$. Residuals from equation (1) are used to estimate the following relationship:

$$
\Delta \mu_{\mathrm{t}}=\rho \mu_{\mathrm{t}-1}+\varepsilon_{\mathrm{t}}
$$

Rejection of the null hypothesis of no co-integration $(\rho \neq 0)$ implies that the residuals in equation (1) are stationary.

Enders and Siklos (2001) argue that if the price transmission is asymmetric, then the standard tests for co-integration and its extensions are mis-specified and therefore they consider an alternative error correction specification that is called the Threshold Autoregressive (TAR) model. Recent developments in time series analysis have recognized the potential for threshold type adjustments in error correction models. This issue has been raised in the past literature on agricultural commodity markets but has not been resolved in the case of the fluid milk market in Turkey and therefore deserves a further attention. Previous studies have tried to characterize the nature of the milk market in Turkey. For instance, Hatirli et al. (2006) focuses on measuring market power and cost efficiency of

\footnotetext{
${ }^{3}$ It was forbidden to sell raw milk to the final consumer during our study period. The government announced a notification regarding the supply of raw milk on the 27th of April, 2017 allowing local retailers to supply raw milk to the final consumers. According to this notification, only the institutions which are free from certain diseases are able to supply raw milk once they have a required permission. Moreover, it is necessary to establish a cold chain to keep raw milk in an appropriate environment for product safety and raw milk has to be sold within 48 hours following the first stage of milking.

${ }^{4}$ During our study period, dairy cooperatives are ineffective in terms of their operational activities. These cooperatives mainly establish a cold chain, collect milk from small milk producers and supply these collected milks to milk processors. Recently, there are only two dairy cooperatives actively supplying/marketing milk and dairy products in the market (Tire Milk Cooperative and Agricultural Credit Unions), but their market shares are very limited.
} 
the fluid milk sector in Turkey. They state that Turkish fluid milk market operates under imperfect competition with increased concentration, higher product differentiation, and greater economies of scale. In the case of fluid milk market, the price transmission is likely to be asymmetric in an imperfectly competitive market structure. Given the imperfectly competitive nature of the milk market, we aim to test for the presence of co-integration with an asymmetric error correction across Turkish fluid milk market. Therefore, we follow the Threshold Autoregressive (TAR) and Momentum Threshold Autoregressive (M-TAR) method of adjustment in our empirical strategy to analyze the price dynamics in Turkey (Enders and Siklos, 2001).

Accordingly, when we incorporate this specification (the Threshold Autoregressive (TAR) model) into the equation (2) we obtain,

$$
\Delta \mu_{\mathrm{t}}=I_{t} \rho_{1} \mu_{\mathrm{t}-1}+\left(1-I_{t}\right) \rho_{2} \mu_{\mathrm{t}-1}+\varepsilon_{\mathrm{t}}
$$

$I_{t}$ is the heavy-side indicator function such that:

$$
I_{t}=\left\{\begin{array}{lll}
1 & \text { if } & u_{t-1} \geq \tau \\
0 & \text { if } & u_{t-1}<\tau
\end{array}\right\}
$$

where $\tau$ is the estimated threshold. This specification allows for an asymmetric adjustment. Here, $\rho_{1}$ and $\rho_{2}$ represent the speed of adjustment coefficients for $\mathrm{RMP}_{\mathrm{t}}$. The long run equilibrium is given by $\Delta \mu_{t}=\tau$. If $\rho_{1}=\rho_{2}$, then the adjustment is said to be symmetric. If the adjustment is not symmetric, a negative asymmetry may occur in the series. If $\rho_{1} \neq \rho_{2}$ and $\Delta \mu_{t}$ is above (under) its long run equilibrium, the adjustment will be given by $\rho_{1}\left(\rho_{2}\right)$. Here, the threshold has a particular importance because it implies that movements toward long run equilibrium do not take place at all points in time but only when the divergence from equilibrium exceeds the threshold (Ghoshray, 2011).

In equation (4), the heavy-side indicator depends on the level of $\mu_{\mathrm{t}-1}$ (Enders and Siklos, 2001). An alternative is suggested by Enders and Granger (1998) and Enders and Siklos (2001) such that, the threshold depends on the previous period changes in $\mu_{\mathrm{t}-1}$ and $\mu_{\mathrm{t}}$ series exhibit more momentum in one direction which is called Momentum Threshold Autoregressive (M-TAR) model. Here, the heavy-side indicator is set by using lagged changes in $\Delta \mu_{\mathrm{t}}$.

$$
I_{t}=\left\{\begin{array}{lll}
1 & \text { if } & \Delta u_{t-1} \geq \tau \\
0 & \text { if } & \Delta u_{t-1}<\tau
\end{array}\right\}
$$

The consistency of equations (1), (4) and (5) allows us to structure an error correction model as following:

$$
\begin{aligned}
\Delta R M P_{t}=\theta & +\varphi^{+} E C T_{t-1}^{+}+\varphi^{-} E C T_{t-1}^{-}+\sum_{i=1}^{n} \alpha^{+} \Delta R M P_{t-i}^{+} \\
& +\sum_{i=1}^{n} \alpha^{-} \Delta R M P_{t-i}^{-}+\sum_{i=1}^{n} \beta^{+} \Delta F G P_{t-i}^{+} \\
& +\sum_{i=1}^{n} \beta^{-} \Delta F G P_{t-i}^{-} \\
& +\vartheta_{t}
\end{aligned}
$$

All the lagged prices (RMP and FGP) are split into the positive and negative components as indicated by "-" and "+" superscripts. The error correction terms "ECT" are constructed from the threshold co-integration regressions in equations (3), (4) and (5). The asymmetry in the adjustment speed is checked by defining disequilibrium terms using $\varphi^{+} \mathrm{ECT}_{\mathrm{t}-1}^{+}$and $\varphi^{-} \mathrm{ECT}_{\mathrm{t}-1}^{-}$. We use $\alpha^{+} \Delta \mathrm{RMP}_{\mathrm{t}-\mathrm{i}}^{+}$and $\alpha^{-} \Delta \mathrm{RMP}_{\mathrm{t}-\mathrm{i}}^{-}$, the lagged retail milk price increases and decreases, respectively, and $\beta^{+} \Delta \mathrm{FGP}_{\mathrm{t}-\mathrm{i}}^{+}$and $\beta^{-} \Delta \mathrm{FGP}_{\mathrm{t}-\mathrm{i}}^{-}$, the lagged farm gate price increases and decreases, respectively, in order to capture the asymmetries in the short run.

\section{Data and empirical results}

In this section, we discuss the relationship between market structure and the asymmetric speed of price adjustment in the Turkish liquid milk market. In order to analyze the price asymmetry in the Turkish dairy sector, we use the logarithms of average monthly farm gate milk prices (FGP) and average monthly retail milk prices (RMP) for the period from January 2003 to December 2016. Average monthly retail milk prices are obtained from Turkish Statistical Institute (Turkstat) and monthly farm gate prices 
are obtained from National Milk Council. As expected, these two variables are likely to be non-stationary. ${ }^{5}$

We estimate the long-run relationship between the two milk prices following the Engle-Granger methodology as specified in equation (1):

$$
\begin{gathered}
\mathrm{RMP}_{\mathrm{t}}=0.6732+1.8352 \mathrm{FGP}_{\mathrm{t}}+\mu_{\mathrm{t}} \\
\text { (34.3258)(72.0891) }
\end{gathered}
$$

where t-values are provided in parentheses.

In Table 1, the residual is used to conduct a unit root test with the specification given in equation (7) in the form of Engle-Granger, TAR, TAR consistent, M-TAR and M-TAR consistent models. We use the thresholds, $\tau=0$ for TAR, $\tau=-0.0766$ for TAR consistent, $\tau=0$ for M-TAR, and $\tau=$ -0.040 for M-TAR consistent. In estimating the threshold values for consistent TAR and M-TAR, we follow the methodology introduced by Chan (1993). We choose 2 lags depending to Akaike criterion (AIC) statistics and we also find that different lag specifications in the models have little impact on the final threshold values selected.

\begin{tabular}{|c|c|c|c|c|c|}
\hline Item & Engle-Granger & TAR & Consistent TAR & $M-T A R$ & $\begin{array}{c}\text { Consistent } \\
\text { M-TAR }\end{array}$ \\
\hline \multicolumn{6}{|l|}{ Estimate } \\
\hline $\operatorname{Threshold}(\tau)$ & NA & 0 & -0.077 & 0 & -0.040 \\
\hline \multirow[t]{2}{*}{$\rho_{1}$} & $-0.208 * * *$ & $-0.133 * *$ & $-0.107^{*}$ & $-0.149 * *$ & $-0.148 * * *$ \\
\hline & $(-4.255)$ & $(-2.174)$ & $(-1.941)$ & $(-2.109)$ & $(-2.852)$ \\
\hline \multirow[t]{2}{*}{$\rho_{2}$} & NA & $-0.310 * * *$ & $-0.429 * * *$ & $-0.251 * * *$ & $-0.481 * * *$ \\
\hline & & $(-4.3753)$ & $(-5.421)$ & $(-4.032)$ & $(-4.503)$ \\
\hline \multirow[t]{2}{*}{$\gamma_{1}$} & 0.046 & 0.059 & $0.100 * * *$ & $0.048 * * *$ & 0.136 \\
\hline & $(0,582)$ & $(0.762)$ & (1.294) & $(0.616)$ & (1.633) \\
\hline \multirow[t]{2}{*}{$\gamma_{2}$} & $0.147^{*}$ & $0.149^{*}$ & $0.171 * *$ & $0.139 *$ & 0.123 \\
\hline & $(1.890)$ & $(1.942)$ & $(2.265)$ & $(1.788)$ & (1.602) \\
\hline AIC & -150.425 & -152.392 & -160.430 & -149.707 & -156.619 \\
\hline$\Phi$ & NA & $11.178^{* * *}$ & $15.754 * * *$ & $9.698^{* *}$ & $13.556^{* * *}$ \\
\hline \multirow[t]{2}{*}{$\rho_{1}=\rho_{2}{ }^{a}$} & NA & 3.9177 & 3.917 & 1.255 & 8.197 \\
\hline & & [0.049] & {$[0.001]$} & {$[0.264]$} & {$[0.005]$} \\
\hline
\end{tabular}

Table 1 - Results of the Engle-Granger and threshold cointegration tests.

Parentheses are the t statistics.

$\Phi$ is the $F$ statistics with the null hypothesis $\rho_{1}=\rho_{2}=0$ with critical values from Wane et al. (2004).

${ }^{a}$ Entries are the sample $F$ statistics for the null hypothesis that the adjustment coefficients are equal. P-values are provided in square brackets.

Three, two and one asterisks (*) denote that the estimated coefficient is statistically significant at, or below, one, five, and ten percent level, respectively.

5 Dickey-Fuller unit root test results are 0,3813 for RMP and -0,1859 for FGP with critical values of -3.4731 for $1 \%,-2.8799$ for $5 \%$ and -2.5765 for $10 \%$. 
As shown in Table 1, the $\mathrm{t}$ statistics for the coefficient of $\mu_{\mathrm{t}-1}$ equals -4.255 . Thus, the Engle-Granger test confirms that the two price series are co-integrated at $1 \%$ level. The nonlinear co-integration analysis is conducted using the threshold autoregression models. The estimated residuals of equation (7) in the form of TAR, TAR consistent, M-TAR and M-TAR consistent models are given in Table 1. The sample value of TAR, TAR consistent and M-TAR consistent models are significant at $1 \%$ level, M-TAR model is significant at $5 \%$ level and $\Phi(\mathrm{F})$ statistics indicate that two series are co-integrated. The null hypothesis that the adjustment coefficients are equal $\left(\rho_{1}=\rho_{2}\right)$ is also rejected for TAR, TAR consistent and M-TAR consistent models. The equality of adjustment coefficients is not rejected only in M-TAR model. Conducting a model selection test, that is the Akaike criterion, we conclude that the TAR consistent model is appropriate one to be selected. Therefore, model estimation results suggest that the TAR consistent model detects the asymmetry better than the other models.

Thus, these results indicate an asymmetric adjustment and suggest that the retail and farm gate prices are co-integrated in Turkey. The values of the adjustment parameters $\left(\rho_{1}\right.$ and $\left.\rho_{2}\right)$ have the correct signs and suggest the convergence. But the estimates also suggest that decreases in farm gate prices are eliminated more quickly compared to the price increases. Positive deviations in the long-term equilibrium resulting from increases or decreases in the prices $\left(\mu_{t-1} \geq-0.077\right)$ are eliminated at a rate of $10.7 \%$ per month. Negative deviations in the long-term equilibrium resulting from increases or decreases in the prices $\left(\Delta \mu_{t-1}<-0.077\right)$ are eliminated at a rate of $42.9 \%$ per month. In other words, positive deviations take about 9 months $(1 / 0.107=9.34$ months $)$ to be fully digested whereas negative deviations take about 2 months $(1 / 0.429=2.33)$ to be ful- ly digested. Therefore, there is a substantially slower convergence for positive (above threshold) deviations from long-run equilibrium compared to negative (below threshold) deviations.

The evidence of an asymmetric co-integration leads to the estimation of the ECM with long-run asymmetric equilibrium. Long-run adjustments are allowed to differ depending on the previous period changes in the long-run error terms. The model of co-integration with TAR consistent adjustment justifies estimation of the error correction model as specified in equation (6). ${ }^{6}$ We estimate the asymmetric error correction model with threshold co-integration and our results are given in Table $2 .{ }^{7}$

Three, two and one asterisks (*) denote that the estimated coefficient is statistically significant at, or below, the one, five, and ten percent level, respectively (the results are based on Newey-West standard errors).

Table 2 - Results of the asymmetric error correction model with threshold co-integration.

\begin{tabular}{|l|l|}
\hline Item & \multicolumn{1}{|c|}{ Estimate } \\
\hline$\Theta$ & $0.004(1.903)^{*}$ \\
\hline$\alpha_{1}^{+}$ & $0.581(5.020)^{* * *}$ \\
\hline$\alpha_{2}^{+}$ & $-0.077(-1.615)$ \\
\hline$\alpha_{1}^{-}$ & $0.659(2.955)^{* * *}$ \\
\hline$\alpha_{2}^{-}$ & $-0.402(-1.119)$ \\
\hline$\beta_{1}^{+}$ & $0.136(1.259)$ \\
\hline$\beta_{2}^{+}$ & $-0.045(-0.391)$ \\
\hline$\beta_{1}^{-}$ & $0.557(2.454)^{* *}$ \\
\hline$\beta_{2}^{-}$ & $0.183(0.681)$ \\
\hline$\varphi^{+}$ & $-0.088(-3.434)^{* * *}$ \\
\hline$\varphi^{-}$ & $0.015(0.113)$ \\
\hline $\mathrm{R}^{2}$ & 0.549 \\
\hline $\mathrm{AIC}$ & -319.257 \\
\hline
\end{tabular}

Note: $t$-values are provided in parentheses.

6 The Granger theorem (Engle and Granger, 1987) indicates that an error correction model can be estimated where all the variables are co-integrated with the assumption that the adjustment process due to disequilibrium among the variables is symmetric. For analyzing asymmetric price transmission, Granger and Lee (1989) decompose error correction terms and first differences on the variables into positive and negative components. In this way, it is possible to know whether positive and negative price differences have asymmetric effects on the dynamic behavior of prices.

${ }^{7}$ Furthermore, the hypotheses of Granger causality between the two prices are assessed with F-tests (not reported in the paper). The F-statistic of 12.8617 and the p-value of 0.0000 reveal that the price of raw milk does Granger cause the price of retail milk. 
As seen from Table 2, the short run coefficients $\alpha^{*}$ and $\beta^{*}$ suggest the presence of price symmetries. Wald tests also confirm this result. ${ }^{8}$ The point estimates of the coefficients for the error correction terms are -0.88 for the positive error correction term (significant at 1\%) and 0.015 for the negative error correction term that is also significant. Therefore, we see that in the short term the price of milk has some different responding speed to positive and negative deviations but the difference is weak for the negative ones. This result may suggest that a threshold specification of the long-run mechanism provides a more plausible representation of the farm gate and retail price relationship.

The insignificant $\varphi^{-}$and significant $\varphi^{+}$suggest that raw milk price increases adjust while price decreases do not adjust in the long run. We also note that the speed of adjustment terms $\left(\varphi^{+}\right.$and $\left.\varphi^{-}\right)$are usually sensitive to the sample period and may have poor small sample properties (Enders and Siklos, 2001). Thus, the corresponding Wald test result has not shown asymmetry for the speed of adjustment terms for error-correction models based on TAR consistent model.

\section{Conclusion}

This paper examines the extent to which increases and/or decreases in farm gate prices during the past years have been transmitted to retail level prices for an important food commodity, fluid milk, in Turkey as a developing country. In this study, we particularly examine the price transmission between raw milk and retail milk markets using the threshold co-integration. We also analyze the price adjustment in the short term through an asymmetric error correction model with a threshold co-integration. The motivation of our research on price transmission is to reveal whether prices are integrated since co-movement of prices in different markets can be interpreted as a sign of efficient markets, while the absence of price co-movement can be viewed as a sign of market failure. Therefore, we aim to determine whether any causal relationships exist among prices in the Turkish fluid milk market.

Our results report the price relationship between these two fluid milk markets over the fourteen years. Accordingly, the transmission between the two prices has been asymmetric in both the long term and short term period of time. The threshold co-integration analysis reveals that in the long term positive deviations of the price spread between the two markets take about 9 months to be fully digested, while negative deviations take about 2 months. Thus, the results state that the nature of asymmetry is captured by the TAR model which suggests that the path of adjustment to the long run equilibrium relation is relatively faster when the price differential is decreasing compared to the case when it is increasing.

Differences between the farm and retail milk prices can exist due to marketing costs across the supply chain and pricing policies associated with the market structure. But, when we look at the long-run relationship between farm gate and retail prices (equation 7), 1 Turkish Lira increase in the farm gate price increases the retail milk price by 1.84 Turkish Lira. This result may indicate a significant market power in the Turkish fluid milk market. Therefore, in this asymmetric case, the deviations can be the reason of the market power of the processors/retailers and the reason of the oligopolistic market structure in the sector.

In Turkey, producers are subject to various restrictions for marketing of raw milk and government intervenes to raw milk prices, therefore the processors/retailers have an unequal bargaining power over the producers. Moreover, producers keep their raw milk products in the cooling tanks, where it stays fresh only for a few days, thus they need to be sold within a short period of time. As the processing industry is concentrated and the structure of unions and cooperatives are ineffective, the producers of raw milk work under contracts and inevitably they have a little bargaining power over the processors. ${ }^{9}$ This implies that the farm price of milk is mainly de-

\footnotetext{
${ }^{8}$ Wald test results (not reported) can be provided upon request from the authors.

${ }^{9}$ Collected milk by the industry (registered milk production) is around $50 \%$ of the total production (Turkstat, milk and milk products various years).
} 
termined by the industry, due to a little market power of the farmers. On the consumption side, the milk can stay fresh for several months on the shelves in UHT (Ultra-High Treatment) packets causing processors/retailers to benefit from a greater elasticity compared to producers. Also, there is no government intervention to the fluid milk market on the consumption side and the prices on the shelves are freely determined.

There is only a small number of big and traditional brands (SEK, Danone, AOC, Yorsan, Ulker, Pinar) in the Turkish milk market and the market structure is highly competitive. The improvements in the UHT technology enable firms to operate with stocks. Therefore, there is a high level of competition in the retailers' shelves. Also, as stated above, there is a big mark-up in pricing the fluid milk products. Therefore, the firms/brands react immediately to price decreases in raw milk and easily transmit the price decreases to their final products. But it is not the case for price increases; the firms/brands do not react quickly to price increases in raw milk products. The profit margin is high enough to compensate the increases in raw milk prices, so the deviation is much slower. This result is consistent with Ward (1982) stating that the market power can lead to negative asymmetric price transmission if oligopolists are reluctant to risk their market share by increasing output prices. Thus, the price response behavior of retailers is found to be consistent with asymmetric price transmission. These findings have profound implications for studying margins along the fluid milk market, therefore ignoring the asymmetry in price transmission is likely to cause calculations of margins to be biased.

In summary, Turkey has the opportunity to improve the dairy sector and to achieve modern standards in the means of production and structure of dairy farms. But the problem arises firstly from the high cost of production (low farm gate prices) and secondly from the high fluid milk prices on the shelves. The effects of high prices on households make it necessary for policy makers to know whether and to what extent farm prices are transmitted to retail prices and its impact on the economy. In the Turkish dairy farms, small farmers face many difficulties for satisfying the capital requirements of buildings and improving a dairy farm structure, and therefore effective marketing and production agricultural cooperatives can be organized to maintain a better market strategy. Moreover, the producers can gain a bargaining power over the processors and also can reach to final consumers directly. This may help to depreciate the power of the processors and the retailers over the producers and consumers improving the production and consumption of milk in Turkey. Finally, we hope that findings reported here will give directions for future qualitative and quantitative studies in Turkey that will systematically guide policy makers to build reforms and regulations improving the fluid milk market structure.

\section{References}

Abdulai A., 2002. Using threshold cointegration to estimate asymmetric price transmission in the Swiss pork market. Applied Economics, 34: 679-687.

Azzam A., 1999. Asymmetry and rigidity in retail-price transmission: a theoretical analysis. American Journal of Agricultural Economics, 81(3): 525-533.

Bailey D., Brorsen B.W., 1989. Price asymmetry inspatial fed cattle markets. Western Journal of Agricultural Economics, 14: 146-252.

Bor O., 2014. Economics of Dairy Farming in Turkey. International Journal of Food and Agricultural Economics, 2(4): 49-62.

Bor O., Ismihan M., Bayaner A., 2014. Asymmetry in farm-retail price transmission in the Turkish fluid milk market. New Medit, 13(2): 2-8.

Brown S., Yucel M., 2000. Gasoline and crude oil prices: why the asymmetry? Economic and Financial Policy Review, Q3: 23-29.

Capitanio F., Adinolfi F., Goodwin B.K., Rivieccio G., 2019. A copula-based approach to investigate vertical shock price transmission in the Italian hog market. New Medit, 18(1): 3-14. http://dx.doi. org/10.30682/nm1901a.

Chan K.S., 1993. Consistency and Limiting Distribution of the Least Squares Estimator of a Threshold Autoregressive Model. The Annals of Statistics, 21(1): 520-533.

Çınar G., 2017. Asymmetric Transmission from Farm Milk Prices to the Yoghurt and Cheese Market. Turkish Journal of Agricultural Economics, 23(1): 93-99.

DairyCo, 2012. Profiting from efficient milk production. Key findings of the Milkbench + dairy bench- 
marking programme regarding the efficiency of dairy production in Britain. Milkbench+ Report.

Dellal İ., Berkum S., 2009. Agricultural Sector Analysis in Turkey and Integration to the EU: Dairy, Tomato, Cereals, Poultry. In: Agricultural Economics Research Institute, Sectoral Analysis: Dairy, Tomato, Cereal, Poultry. Publication No. 171. Ankara: AERI, pp. 1-8.

Enders W., Granger C.W.J., 1998. Unit-Root Tests and Asymmetric Adjustment with an Example Using the Term Structure of Interest Rates. Journal of Business and Economic Statistics, 16: 304-311.

Enders W., Siklos P.L., 2001. Cointegration and Threshold Adjustment. Journal of Business and Economic Statistics, 19(2): 166-176.

Engle R.F., Granger C.W.J., 1987. Cointegration and Error Correction: Representation, Estimation and Testing. Econometrica, 55: 251-276.

FAO, 2014. Faostat Database. http://faostat.fao.org.

Frey J., Manera M., 2007. Econometric Models of Asymmetric Price Transmission. Journal of Economic Surveys, 21: 449-415.

Ghoshray A., 2002. Agricultural Economics Society Prize Essay Asymmetric Price Adjustment and the World Wheat Market. Journal of Agricultural Economics, 53(2): 299-317.

Ghoshray A., 2008. Asymmetric Adjustment of Rice Export Prices: The Case of Thailand and Vietnam. International Journal of Applied Economics, 5(2): 80-91.

Ghoshray A. 2011. Underlying Trends and International Price Transmission of Agricultural Commodities. ADB Economics Working Paper Series No. 257. Manila: Asian Development Bank.

Granger C.W.J., Lee T.H., 1989. Investigation of Production, Sales and Inventory Relationships Using Multicointegration and Non-Symmetric Error Correction Models. Journal of Applied Econometrics, 4(S1): 145-159. https://doi.org/10.1002/ jae.3950040508.

Hahn W., 1990. Price Transmission Asymmetry in pork and beef markets. The Journal of Agricultural Economics Research, 42: 21-30.

Hatirli S.A., 2004. Is the fluid milk subsector competitive in Turkey. Turkish Journal of Veterinary and Animal Sciences, 28: 663-668.
Hatirli S.A., Ozkan B., Jones E., Aktas A.R., 2006. Application of measuring market power and cost efficiency in the milk sub-sector in Turkey compared to other European countries. Trends in Food Science \& Technology, 17(7): 367-372.

Jaffry S., 2004. Asymmetric Price Transmission: A Case Study of the French Hake Value Chain. Marine Resource Economics, 19(4): 511-523.

Kinnucan H., Forker O., 1987. Asymmetry in farm-retail price transmission for major dairy products. American Journal of Agricultural Economics, 69: 285-292.

Lloyd T., McCorriston S., Morgan W., Rayner T., 2006. Food Scares, Market Power and Price Transmission: the UK BSE Crisis. European Review of Agricultural Economics, 33(2): 119-147.

Meyer J., von Cramon-Taubadel S., 2004. Asymmetric Price Transmission: a survey. Journal of Agricultural Economics, 55(3): 581-611.

Miller D.J., Hayenga M.L., 2001. Price Cycles and Asymmetric Price Transmission in the US Pork Market. American Journal of Agricultural Economics, 83(3): 551-562.

Peltzman S., 2000. Prices rise faster than they fall. Journal of Political Economy, 108: 466-502.

SIS, 2014. Turkish Statistical Institute, various agricultural statistics. www.tuik.gov.tr.

Tekgüç H., 2013. Oligopoly and Price Transmission in Turkey's Fluid Milk Market. Agribusiness, 29(3): 293-305.

Turkstat (Turkish Statistical Institute), 2016. Statistical files. www.tuik.gov.tr.

Vavra P., Goodwin B.K., 2005. Analysis of price transmission along the food chain. OECD Food, Agriculture and Fisheries Papers, No. 3. Paris: OECD Publishing.

Wane A., Gilbert S., Dibooglu S., 2004. Critical Values of the Empirical F-Distribution for Threshold Autoregressive and Momentum Threshold Autoregressive Models. Discussion Papers, Department of Economics, Southern Illinois University Carbondale. Paper 23. http://opensiuc.lib.siu.edu/ econ_dp/23.

Ward R.W., 1982. Asymmetry in retail, wholesale, and shipping point pricing for fresh vegetables. American Journal of Agricultural Economics, 62: 205-212. 